\title{
The Origin of a Linear Mitochondrial Plasmid (mF) that Promotes Mitochondrial Fusion in Laboratory Strains of Physarum polycephalum
}

\author{
By Shigeyuki Kawano, ${ }^{+}$Takashi ABE, Kimie Mori, and Hiroyoshi TaKano \\ Department of Biological Sciences, Graduate School of Science, University of Tokyo, Hongo, Bunkyo-ku, Tokyo 113 \\ (Communicated by Noburô KamiYA, M. J. A., Sept. 12, 1997)
}

\begin{abstract}
The mitochondrial-fusion promoting $(\mathrm{mF})$ plasmid first found in the slime mold Physarum polycephalum is a parasitic, selfish mitochondrial plasmid, and is capable of manipulating mitochondria behavior as indicated by its name. To investigate the origin of the $\mathrm{mF}$ plasmid, we collected many Physarum laboratory strains as are available at present throughout the world, and classified their origin on the basis of the results of mating-type analysis and restriction endonuclease analysis of their mtDNA. They include 8 plasmodial strains obtained from mating crosses with 22 different myxamoebal strains and two sclerotia. One of the two sclerotia is originated at W. Seifriz'z laboratory in the University of Pennsylvania, and is the oldest laboratory strain in the world. The mtDNA of each strain formed a single $80-90 \mathrm{kbp}$ band but the $\mathrm{mF}^{+}$strains yielded a $14-16 \mathrm{kbp} \mathrm{mF}$ plasmid band in addition to this main band. Southern hybridization using labeled plasmid DNA as the probe allowed the $\mathrm{mF}^{-}$strains to be classified into two categories: simple $\mathrm{mF}^{-}$having only an mID sequence and $\Delta \mathrm{mF}$ having some part of the $\mathrm{mF}$ plasmid integrated into the mtDNA. The mID sequence is almost identical to a 475bp sequence ( $\mathrm{pID}$ ) of the $\mathrm{mF}$ plasmid. To confirm this finding, we designed PCR primers for amplifying certain parts of the $\mathrm{mF}$ plasmid. This PCR system enabled us to determine whether apparent $\mathrm{mF}^{-}$strains and sclerotia possessed the free or integrated $\mathrm{mF}$ plasmids. The sclerotium derived from Seifriz's laboratory is simple $\mathrm{mF}^{-}$, but the other sclerotium, which was originally derived from the North Carolina Biological supply house is complete $\mathrm{mF}^{+}$. Moreover, except this derivative of North Carolina Biological, DP12 $\times \mathrm{DP} 13$, which derived from a stock at the University of Iowa is $\Delta \mathrm{mF}$. Such scattered distribution of $\mathrm{mF}^{+}$and $\Delta \mathrm{mF}$ suggests that the mitochondria occasionally acquired the $\mathrm{mF}$ plasmid after the establishment of $P$. polycephalum as a species.
\end{abstract}

Key words: Plasmid; origin; mitochondria; fusion; Physarum polycephalum.

Introduction. Linear and circular mitochondrial plasmids are common in natural isolates of fungi and plants. ${ }^{1)}$ Their definitive function remains obscure although they have been extensively studied and a number of them have been sequenced. Such plasmids are interesting in themselves as examples of selfish or parasitic DNA. They may also provide insights into the biology and evolution of their hosts, mitochondria.

Separate strains of the true slime mold, Physarum polycephalum, whose mitochondria fuse and do not fuse were isolated, and these mitochondria were the first to show evidence of a relationship between fusion and recombination. All strains of $P$. polycephalum that display mitochondrial fusion possess a specific mitochondrialplasmid, in other words, this plasmid promotes mitochondrial fusion. ${ }^{2)}$ This mitochondrial-fusion-promoting $(\mathrm{mF})$

†) Correspondence to: S. Kawano. plasmid has a 475-bp sequence (pID) that is identical to a 479-bp sequence (mID) of mtDNA, with the exception of deletions of a total of only four base pairs at three sites. ${ }^{3)}$ With these identical sequences, the $\mathrm{mF}$ plasmid is constitutively crossed over with mtDNA to integrate itself into the mtDNA. This is very similar to that proposed as the initial stage in the evolution of sex, as pointed out by Hurst (1991). ${ }^{4)}$ The existence of the $\mathrm{mF}$ plasmid may serve as direct support for the idea that parasitic, selfish genes are capable of manipulating their hosts (mitochondria) in the manner proposed by Hickey and Rose (1988). ${ }^{5}$

To investigate the origin of $\mathrm{mF}$ plasmid, in the present study, we collected many Physarum laboratory strains as are available at present throughout the world, and classified their origin on the basis of the results of mating-type analysis and restriction endonuclease analysis of their mtDNA. The trace harboring the $\mathrm{mF}$ plasmid was found in only two original strains. 
Table I. List of plasmodial strains of $P$. polycephalum classified by mtDNA RFLPs and PCR of the $\mathrm{mF}$ plamid

\begin{tabular}{|c|c|c|c|c|c|c|c|}
\hline \multirow{3}{*}{\multicolumn{2}{|c|}{ Plasmodial strain }} & \multicolumn{2}{|c|}{ mtDNA } & \multicolumn{4}{|c|}{$\mathrm{mF}$ Plasmid } \\
\hline & & \multirow[t]{2}{*}{ Type } & \multirow[t]{2}{*}{$\mathrm{mID}^{1)}$} & \multirow[t]{2}{*}{ Free } & \multicolumn{3}{|c|}{ Integrated $\mathrm{mF}$} \\
\hline & & & & & Sou $^{2)}$ & $\mathrm{pID}^{3)}$ & $\operatorname{ter}^{4)}$ \\
\hline 1 & NG7×RA669 & $\mathrm{N} 7+\mathrm{P}$ & yes & yes & com & yes & yes \\
\hline 2 & OZ12×RA669 & $\mathrm{RM}+\mathrm{P}$ & yes & yes & com & yes & yes \\
\hline 3 & OZ35 $\times$ RA669 & $\mathrm{RM}+\mathrm{P}$ & yes & yes & com & yes & yes \\
\hline 4 & NG11×RA669 & $\mathrm{N} 11+\mathrm{P}$ & yes & yes & com & yes & yes \\
\hline 5 & $\mathrm{NG} 7 \times \mathrm{OX} 110$ & $\mathrm{RM}+\mathrm{P}^{5)}$ & yes & yes & com & yes & yes \\
\hline 6 & NG7×OX115 & N7 & yes & no & del & no & yes \\
\hline 7 & NG27×RA669 & N27 & yes & no & del & no & yes \\
\hline 8 & NG19×RA669 & N19 & yes & no & del & no & yes \\
\hline 9 & NG15×RA669 & N15 & yes & no & del & no & yes \\
\hline 10 & HI10×RA669 & $\mathrm{H} 10$ & yes & no & del & no & yes \\
\hline 11 & HI14×RA669 & $\mathrm{H} 14$ & yes & no & del & no & yes \\
\hline 12 & $\mathrm{NC} 8 \times \mathrm{RA} 669$ & B8 & yes & no & del & no & yes \\
\hline 13 & $\mathrm{DP} 12 \times \mathrm{DP} 13$ & I & yes & no & del & no & yes \\
\hline 14 & DP14×DP15 & WA & yes & no & no & no & no \\
\hline 15 & DP74×DP75 & B7 & yes & no & no & no & no \\
\hline 16 & DP89×DP90 & $\mathrm{W}$ & yes & no & no & no & no \\
\hline 17 & OS60 $\times$ RA669 & $\mathrm{O}$ & yes & no & no & no & no \\
\hline 18 & $\mathrm{OX} 110 \times \mathrm{OX} 115$ & $\mathrm{M}$ & yes & no & no & no & no \\
\hline 19 & Sclero 1 & $-6)$ & yes & - & - & no & no \\
\hline 20 & Sclero 2 & - & yes & - & - & yes & yes \\
\hline
\end{tabular}

1)-4) "mID", "Sou", "pID", and "ter" indicate the results of PCR with mID primers, Southern hybridization, and PCR with $\mathrm{pID}$ and ter primers, respectively. ${ }^{5)}$ The free $\mathrm{mF}$ plasmid was not detected on the agarose gel stained with ethidium bromide but was detected by PCR. ${ }^{6)}$ The mtDNA from sclerotia could not be analyzed by agarose gel electrophoresis and Southern hybridization.

Materials and methods. Strains. The plasmodial and myxamoebal strains of Physarum polycephalum are listed in Tables I and II, respectively. ${ }^{6), 7)}$ Two pieces of sclerotia were obtained from N. Kamiya (Osaka University, Sclero 1) and F. Matsumura (Nagoya University, Sclero 2). Plasmodia were cultured on MEA plates, on wet filter paper with compressed oats, and in semi defined liquid medium (SDM) as microplasmodia. ${ }^{8), 9)}$ Sporulation and germination of spores were induced as described previously. ${ }^{8), 9)}$ Myxamoebae were cultured with Escherichia coli on SM-1 plates. ${ }^{8)}$

Genotype analysis. The myxamoebal progeny of plasmodia were tested for their ability to form plasmodia in mating-type analysis with tester strains representative of certain known matA and matB alleles. ${ }^{8), 10)}$ Two distinct mitochondrial phenotypes, mitochondrial fusion $\left(\mathrm{mif}^{+}\right)$and mitochondrial fusion-deficient ( mif $^{-}$) were classified to observe the frequency of mitochondrial fusion in the spores. ${ }^{2), 11)}$

Restriction endonuclease analysis. mtDNA was isolated from myxamoebal and plasmodial strains by density centrifugation on Hoechst $33258 / \mathrm{CsCl}^{12)}$ The isolated
mtDNA was analyzed with certain restriction endonucleases also as described previously. ${ }^{2)}$ Southern hybridization analysis with the ECL labeling kit (Amersham) was carried out as described previously. ${ }^{11)}$

$P C R$ analysis. Three pairs of primers that amplify the DNA regions of identical sequences of mtDNA (mID) and the $\mathrm{mF}$ plasmid ( $\mathrm{pID}$ ), and the terminal region of the $\mathrm{mF}$ plasmid (ter) were used here. The primers of mID 1 and 2 are 5'GTTACTCTACCCGAATATCC $3^{\prime}$ and 5'CTATCCTGCTCATTTATGTC3'; the primers of pID 1 and 2 are 5'GGATCCTTTTCATCGTAGCAC3' and 5'CTCGGCATTTCCAAGATATA $3^{\prime}$; the primers of ter 1 and 2 are $5^{\prime} \mathrm{T}$ CCTTCTTCCGAAAATTTGG3' and 5'CGTAATAGACAGTTAACACG3'. Polymerase chain reaction (PCR) with Taq polymerase (Takara Ex Taq, Takara Shuzo Co., Ltd., Japan) was performed in an automated Thermal Cycler according to the condition recommended by the manufacture (Takara). Total DNA of sclerotia for PCR was extracted with phenol and chloroform from small pieces of Sclero 1 and 2 which were soaked in Tris Saline EDTA (100 mM Tris- $\mathrm{HCl} \mathrm{pH} \mathrm{8.0,} 150 \mathrm{mM} \mathrm{NaCl}, 100$ mM EDTA) including $2 \%$ SDS. 
Table II. List of myxamoebal strains of $P$. polycephalum classified by mating type, $\mathrm{mF}$ plasmid, and origin of laboratory strains

\begin{tabular}{|c|c|c|c|c|}
\hline Amoebal strain & Genotype & mtDNA type & Plasmid & Origin \\
\hline \multicolumn{5}{|l|}{ Group I } \\
\hline Sclero 1 & & - & $\mathrm{mF}^{-}$ & Pennsylvania \\
\hline \multicolumn{5}{|l|}{ Progeny of Os-1 } \\
\hline OS60 & matA18matB14 mif $^{-}$ & $\mathrm{O}$ & $\mathrm{mF}^{-}$ & Osaka \\
\hline \multicolumn{5}{|l|}{ Group II } \\
\hline Sclero 2 & & - & $\mathrm{mF}^{+}$ & North Carolina \\
\hline \multicolumn{5}{|l|}{ Progeny of $\mathrm{Ng}$} \\
\hline NG7 & matA12matB6 mif $^{+}$ & $\mathrm{N} 7+\mathrm{P}$ & $\mathrm{mF}^{+}$ & Nagoya \\
\hline NG11 & matA11matB5 mif $^{+}$ & $\mathrm{N} 11+\mathrm{P}$ & $\mathrm{mF}^{+}$ & Nagoya \\
\hline NG15 & matA12matB5 mif - $^{-}$ & N15 & $\Delta \mathrm{mF}$ & Nagoya \\
\hline NG19 & matA12matB6 mif $^{-}$ & N19 & $\Delta \mathrm{mF}$ & Nagoya \\
\hline NG27 & matA11matB5 mif $^{-}$ & N27 & $\Delta \mathrm{mF}$ & Nagoya \\
\hline \multicolumn{5}{|l|}{ Progeny of $\mathrm{Hi}$} \\
\hline HI10 & matA12matB6 mif $^{-}$ & $\mathrm{H} 10$ & $\Delta \mathrm{mF}$ & Hitotsubashi \\
\hline HI14 & matA11matB5 mif $^{-}$ & H14 & $\Delta \mathrm{mF}$ & Hitotsubashi \\
\hline \multicolumn{5}{|c|}{ Progeny of $N G \times R A$} \\
\hline OZ12 & matA12matB6 mif $^{+}$ & $\mathrm{RM}+\mathrm{P}$ & $\mathrm{mF}^{+}$ & Nagoya/McArdle \\
\hline OZ35 & matA12matB6 mif $^{+}$ & $\mathrm{RM}+\mathrm{P}$ & $\mathrm{mF}^{+}$ & Nagoya/McArdle \\
\hline \multicolumn{5}{|l|}{ Progeny of $\mathrm{Nc}$} \\
\hline $\mathrm{NC} 8$ & matA12matB5 mif $^{-}$ & B8 & $\Delta \mathrm{mF}$ & North Carolina \\
\hline \multicolumn{5}{|c|}{ Group III; Colonia isogenic } \\
\hline XO110 & matA2matB1 mif ${ }^{-}$ & M & $\mathrm{mF}^{-}$ & McArdle/Indiana \\
\hline XO115 & matA3matB1 mif $^{-}$ & M & $\mathrm{mF}^{-}$ & McArdle/Indiana \\
\hline RA669 & matA1matB4 mif ${ }^{-}$ & M & $\mathrm{mF}^{-}$ & McArdle/Indiana \\
\hline \multicolumn{5}{|c|}{ Group IV; DP-series } \\
\hline DP12 & matA5matB10 mif $^{-}$ & I & $\Delta \mathrm{mF}$ & Iowa \\
\hline DP13 & matA6matB11 mif $^{-}$ & I & $\Delta \mathrm{mF}$ & Iowa \\
\hline DP14 & matA7matB7 mif $^{-}$ & WA & $\mathrm{mF}^{-}$ & Ward \\
\hline DP15 & matA8matB8 mif $^{-}$ & WA & $\mathrm{mF}^{-}$ & Ward \\
\hline DP74 & matA12matB5 mif $^{-}$ & B7 & $\mathrm{mF}^{-}$ & Boreal \\
\hline DP75 & matA11matB6 mif $^{-}$ & B7 & $\mathrm{mF}^{-}$ & Boreal \\
\hline DP89 & matA15matB12 mif ${ }^{-}$ & $\mathrm{W}$ & $\mathrm{mF}^{-}$ & Wisconsin \\
\hline DP90 & matA16matB13 mif $^{-}$ & $\mathrm{W}$ & $\mathrm{mF}^{-}$ & Wisconsin \\
\hline
\end{tabular}

Results. We obtained 22 amoebal strains, which are available as laboratory strains (Table II) and two sclerotia which may be original strains of the OS series (Sclero 1) and NG series (Sclero 2) ${ }^{6}{ }^{6}$ Each natural isolate tends to carry two different alleles for matB locus as well as for the matA locus. ${ }^{7)}$ To verify the origin of these laboratory strains, we identified $m a t A$ and $m a t B$ alleles of all strains used except Sclero 1 and 2 (Table II), neither of which could be revived by any available means because they had been stocked for at least 56 and 16 years, respectively. Every amoebal strain investigated here was confirmed to have specific mat $A$ and matB alleles that identify the source of the isolate (Table II).

The extent of restriction fragment length polymorphisms (RFLPs) in mtDNA among these strains of $P$. polycephalum provides a useful source of cytoplasmic genetic markers that indicate the origin of the isolate. ${ }^{8)}$ To confirm the origin of the strains used here on the basis of mtDNA RFLPs, we obtained 18 plasmodial strains by inbreeding and outbreeding with RA669, OX110, and OX115, and isolated their mtDNA. In matA hierarchy in transmission pattern of mtDNA, ${ }^{13)}$ the myxamoebal strain RA669 (matA1matB4) locates in the lower status and plays as male with respect to the transmission of mtDNA. ${ }^{13)}$ This allows us to directly determine the RFLPs of other myxamoebal strains from the mtDNA of the plasmodia yielded by the mating cross with RA669. Fig. 1b shows the patterns of HindIII restriction fragments of mtDNA from 18 representative plasmodial strains. Sixteen distinct types of mtDNA were detected (Table I). The fragments specific for the strains having the free $\mathrm{mF}$ plasmid $\left(\mathrm{mF}^{+}\right)$cannot be detected at first glance (Fig. 1b). However, agarose gel 


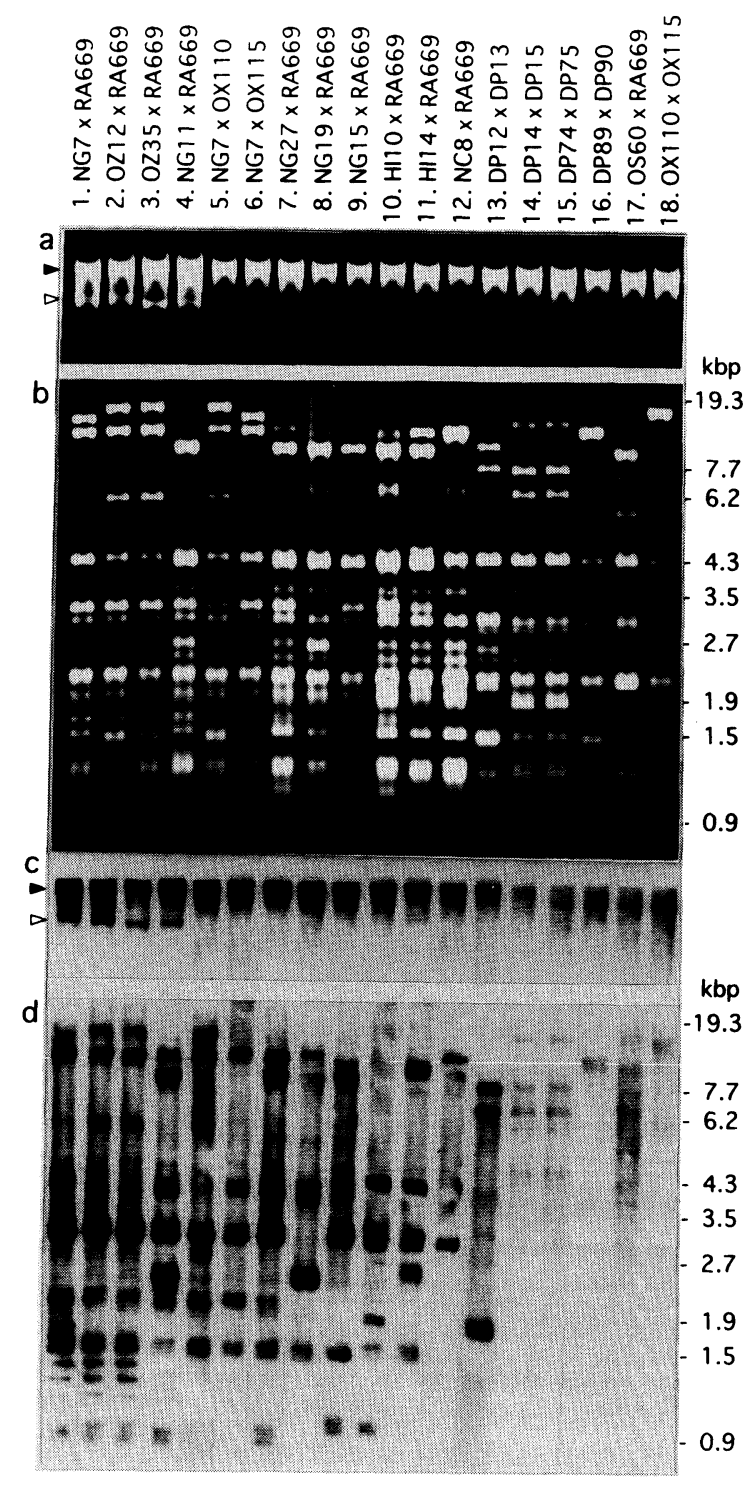

Fig. 1. Profiles of undigested (a) and HindIII-digested (b) mtDNAs from 18 plasmodial strains after electrophoresis on agarose gels. Southern hybridization of the same gels was carried out using labeled plasmid DNA as the probe (c and d). Closed and open arrowheads indicate bands of mtDNA and the $\mathrm{mF}$ plasmid, respectively. Lanes $1-4$ are $\mathrm{mF}^{+}$, lanes 5-13 are $\Delta \mathrm{mF}$, and lanes 14-18 are $\mathrm{mF}^{-}$. The plasmodial strains used here are listed in Table I. The plasmodial strain of lane 5 (NG7×OX110) was later confirmed to be $\mathrm{mF}^{+}$by PCR.

electrophoresis of undigested mtDNA (Fig. 1a) allowed classification of the mtDNAs into two types according to whether they are $\mathrm{mF}^{+}$or $\mathrm{mF}^{-}$. The mtDNA of each $\mathrm{mF}^{+}$ strain also formed a single band of $80-90 \mathrm{kbp}$, but, in addition to this main band, $\mathrm{mF}^{+}$strains yielded a second band of approximately $14-16 \mathrm{kbp}^{2), 14)}$

Southern hybridization using labeled plasmid DNA as

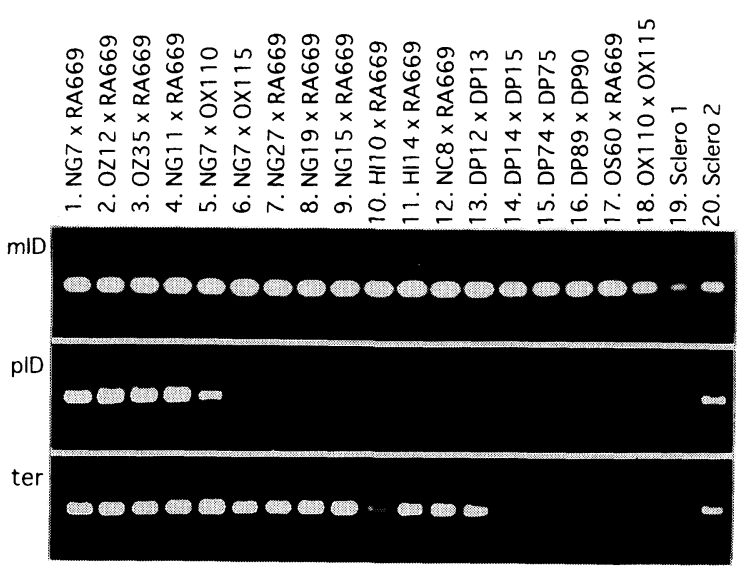

Fig. 2. Profiles after electrophoresis on agarose gels of PCR products obtained with mID 1 and 2 primers (mID), pID 1 and 2 primers (pID), and ter 1 and 2 primers (ter), which amplify $317 \mathrm{bp}, 1130 \mathrm{bp}$, and $769 \mathrm{bp}$ of both identical sequences of $\mathrm{mtDNA}(\mathrm{mID})$ and the $\mathrm{mF}$ plasmid (pID), and a near terminal region of the $\mathrm{mF}$ plasmid, respectively. Lanes $1-5$ and 20 are $\mathrm{mF}^{+}$, lanes $6-13$ are $\Delta \mathrm{mF}$, and lanes $14-19$ are $\mathrm{mF}^{-}$. The plasmodial strains used here are listed in Table I.

the probe was carried out to determine whether any of the sequences of the $\mathrm{mF}$ plasmid were represented in the mitochondrial genomes of the $\mathrm{mF}^{-}$strains. The labeled plasmid probe hybridized to some bands of mtDNA not only in all of the $\mathrm{mF}^{+}$strains but in some of the $\mathrm{mF}^{-}$ strains as well (Fig. 1d). This suggests that a portion of the $\mathrm{mF}$ plasmid integrated into $\mathrm{mtDNA}$ is deleted in some $\mathrm{mF}^{-}$ strains. Moreover, in $\mathrm{mF}^{-}$strains not having strong hybridized bands, the probe faintly hybridized to the whole mitochondrial genome (Fig. 1c) and the largest HindIII fragment of the mitochondrial genome (Fig. 1d). This suggests that the mtDNA of not only $\mathrm{mF}^{+}$but $\mathrm{mF}^{-}$ possesses an $\mathrm{mID}$ sequence. Accordingly, the $\mathrm{mF}^{-}$strains were classified into two categories: simple $\mathrm{mF}^{-}$having only the $\mathrm{mID}$ sequence and $\Delta \mathrm{mF}$ having some part of the $\mathrm{mF}$ plasmid integrated into mtDNA.

To confirm the results of Southern hybridization, we designed PCR primers to amplify a part (317 bp) of the mID sequence of M-type mtDNA. Fig. 2 shows that the mID primers could amplify mID sequences in the mtDNA of all strains, including Sclero 1 and 2 (lanes 19 and 20 in $\mathrm{mID}$ ). The mtDNAs for Sclero 1 and 2 used here were small amounts of degraded total DNA extracted from pieces of Sclero 1 and 2 . This finding not only confirms that the mtDNA of all strains possesses the mID sequence but shows that a specific sequence of mtDNA, such as $\mathrm{mID}$, could be amplified by our PCR system using the degraded total DNA of sclerotia. Fig. 2 also shows the results of $\mathrm{PCR}$ using $\mathrm{pID}$ and ter primers. Since the pID primers 
amplify the sequence $(1,130 \mathrm{bp})$ including border sequences of $\mathrm{pID}$, only free $\mathrm{mF}$ plasmids not integrated $\mathrm{mF}$ plasmids can be detected by using them (Table I). On the other hand, since the ter primers amplify the sequence (769 bp) that locates in the near terminal region of the $\mathrm{mF}$ plasmid, the $\mathrm{mF}$ plasmid can be detected regardless of whether integrated or free (Table I). Therefore, the PCR system using these two pairs of primers allows determination of whether apparent $\mathrm{mF}^{-}$strains and sclerotia contain the free and integrated $\mathrm{mF}$ plasmid. For example, this PCR system showed the free $\mathrm{mF}$ plasmid in NG7 $\times$ OX110 (lane 5 in Fig. 2), instead of the presence of a complete sequence of the integrated $\mathrm{mF}$ plasmid, although its presence was not detected by either agarose gel electrophoresis of mtDNA or Southern hybridization (lane 5 in Fig. 1). Furthermore, the results shown in lanes 19 and 20 of Fig. 2 confirmed that Sclero 1 is simple $\mathrm{mF}^{-}$but Sclero 2 is complete $\mathrm{mF}^{+}$.

Discussion. $P$. polycephalum appears to be characterized by three unique alleles at each of the unlinked multiallelic, mating-type loci mat $A$, matB, and matC, ${ }^{15)-17)}$ making mating-type alleles good markers of nuclear genes for determining the particular isolate from which any given strain is derived. To cross efficiently, myxamoebae must carry different alleles, at least at $m a t A$ and $m a t B$. For each of these loci, full compatibility results when any two alleles are combined among a set of at least fifteen. Each natural isolate tends to carry two different alleles at matB as well as at the mat $A$ locus. ${ }^{7)}$ In this study, 22 amoebal strains that had been mated to form 18 plasmodia and two sclerotia were classified into four groups according to mating types (Table II). Although the two sclerotia could not be revived, Sclero 1 and 2 were included in Group I and II, respectively. Based on its mating type and mtDNA type, we have practically confirmed that a plasmodial strain, Os1 originated at Seifriz's laboratory in the University of Pennsylvania. ${ }^{6)}$ Since Os-1 is thought to be one of the plasmodial strains descended from Sclero 1 at Kamiya's laboratory in Osaka University, Sclero 1 was classified in the same group as OS60 (Table II). This group is the oldest laboratory strain in the world. ${ }^{6)}$

The extent of mtDNA RFLPs among the strains of $P$. polycephalum is higher than in other organisms and provides a useful source of cytoplasmic genetic markers. ${ }^{18)}$ The mtDNA types are usually consistent with the mating types and the isolate origins of myxamoebal strains, as shown in Group IV (Table II). On the other hand, although all myxamoebal strains included in Group II have the same combination of mating types (matA11, 12, matB5, 6), their mtDNA types varied considerably (lanes 1-12 in Fig. 1,
Tables I and II). This is because they have harbored or currently harbor the $\mathrm{mF}$ plasmid. Some $\Delta \mathrm{mF}$ strains harbor certain sequences of the integrated $\mathrm{mF}$ plasmid in spite of being determined to be if $^{-}$and $\mathrm{mF}^{-}$according to the phenotype of mitochondrial fusion and the results of restriction endonuclease analysis (Table II). Takano et al. $(1996)^{9)}$ have shown that recombination occurs between only 12-nucleotide or six repeats of AAT of homologous sequences in both mtDNA and the integrated $\mathrm{mF}$ plasmid, and the regions lying between these homologous sequences are deleted to yield various mtDNA RFLPs. $\Delta \mathrm{mF}$ seems to be caused by such deletions combined with a marked decrease in free $\mathrm{mF}$ plasmids, as shown in $\mathrm{NG} 7 \times \mathrm{OX} 110$. The presence of some $\Delta \mathrm{mF}$ strains in Group II suggests that this deletion combined with loss of the free $\mathrm{mF}$ plasmid occurs frequently.

The free $\mathrm{mF}$ plasmid was first found in NG7, a progeny of the plasmodial strain $\mathrm{Ng}^{2}{ }^{2}$ However, it is impossible to determine whether $\mathrm{Ng}$ contains the free $\mathrm{mF}$ plasmid, since the original strain cultured at Nagoya University was ruined for itself for aging. Japanese Physarumists mainly used three plasmodial strains that had descended from strains in Seifriz's laboratory, and the Ward Biological and North Carolina Biological supply houses. ${ }^{6)}$ Neither Sclero 1 derived from Seifriz's laboratory nor the amoebal strains (DP14 and DP15) derived from Ward Biological have the $\mathrm{mF}$ plasmid. Only Sclero 2, a progenitor of $\mathrm{Ng}$ derived from North Carolina Biological, according to the mating types has the free $\mathrm{mF}$ plasmid (Table II). These findings suggest that the origin of the $\mathrm{mF}$ plasmid is North Carolina Biological. However, the amoebal strains (HI10, HI14, and NC8) isolated from the plasmodia from North Carolina Biological are $\Delta \mathrm{mF}$ but contain no free $\mathrm{mF}$ plasmids. It is possible that only one plasmodium purchased from North Carolina Biological during a very limited period had the free $\mathrm{mF}$ plasmid.

When Collins $(1975)^{20)}$ first analyzed the matA alleles of plasmodia, he found that the plasmodium from North Carolina Biological carried the matA9 and matA10 alleles and that the Turtox plasmodium carried the matA11 and matA12 alleles. However, Kirouac-Brunet et al. (1981) ${ }^{7)}$ obtained plasmodia from the North Carolina, Turtox, and Boreal Biological supply houses in 1978 and found that they all contain the same four alleles: matA11, matA12, matB5, and matB6. Kawano et al. $(1987)^{18)}$ also confirmed that the plasmodium from North Carolina Biological had been replaced by the plasmodium that was originally known as "Turtox isolate" (matA11, 12; matB5, 6). The myxamoebal strains (DP74 and DP75) derived from the Boreal plasmodium replaced by the Turtox isolate at almost same 
time as North Carolina Biological were confirmed to be simple $\mathrm{mF}^{-}$in this study (Table II). This shows that the Turtox isolate did not have the free $\mathrm{mF}$ plasmid at least until it was transplanted to North Carolina Biological.

$\mathrm{DP} 12$ and DP13 are $\Delta \mathrm{mF}$ and contain some regions of the integrated $\mathrm{mF}$ plasmid (Table II). This shows that the free $\mathrm{mF}$ plasmid was present in their progenitor. Their original strains are Ppll.1.17-100 and Ppll.1.17-80, which were isolated by Collins $(1975)^{20)}$ from a stock at the University of Iowa. This stock may be derived from materials collected by Howard $(1931)^{21)}$ while at the University of Iowa. There is no evidence showing that these strains were related to the North Carolina plasmodium. There may be two lines having the free $\mathrm{mF}$ plasmid. Such scattered distribution of the free $\mathrm{mF}$ plasmid suggests that its origin is not evolutional but occasional.

At first glance this seems to be inconsistent with the fact that the $\mathrm{mF}$ plasmid has a sequence (pID) that is almost completely identical to that of mtDNA (mID). This $\mathrm{mID}$ is common to the mtDNA of all strains (Table I). The homology between the sequences of $\mathrm{pID}$ and $\mathrm{mID}$ suggests a common origin for these sequences. It is reasonable to conclude that the $\mathrm{mF}$ plasmid was integrated into the mtDNA and that almost all of the sequences of the integrated $\mathrm{mF}$ plasmid were subsequently deleted leaving a very short sequence such as $\mathrm{pID}$ in the mtDNA, i.e., $\mathrm{mID}$ originated in $\mathrm{pID}$. Alternatively, the $\mathrm{mF}$ plasmid acquired $\mathrm{mID}$ from the mtDNA after its entry into a mitochondrion i.e. $\mathrm{pID}$ originated in $\mathrm{mID}^{22)}$ Since all strains of $P$. polycephalum possess $\mathrm{mID}$, if the former hypothesis is true, the origin of the $\mathrm{mF}$ plasmid should be older than the establishment of $P$. polycephalum as a species. However, the scattered distribution of the free $\mathrm{mF}$ plasmid shown in this work suggests that the mitochondria occasionally acquired the $\mathrm{mF}$ plasmid after the establishment of $P$. polycephalum. To trace the true origin of the $\mathrm{mF}$ plasmid, in the future, we will need sequential information on $\mathrm{mID}$ and $\mathrm{pID}$ based on such a pedigree analysis of Physarum laboratory strains.

Acknowledgments. We are grateful to Prof. N. Kamiya, M. J. A., for providing a Seifriz's plasmodial strain preserved as sclerotia (Sclero 1) Mar. 31, 1941 and its historical information, and to Dr. H. Matsumura for providing an original Nagoya strain preserved as sclerotia (Sclero 2) early in the 1980's. We thank Prof. T. Kuroiwa for many stimulating and critical discussions. This work was supported by a Grant for Special Promoted Research (project no. 06101002) from the Ministry of Education, Science, Sports and Culture of Japan.

\section{References}

1) Kawano, S., Takano, H., and Kuroiwa, T. (1995) Int. Rev. Cytol. 161, 49-110.

2) Kawano, S., Takano, H., Mori, K., and Kuroiwa, T. (1991) Protoplasma 160, 167-169.

3) Takano, H., Kawano, S., and Kuroiwa, T. (1992) Curr. Genet. 22, 221-227.

4) Hurst, L. D. (1991) Nature 354, 23-24.

5) Hickey, D. A., and Rose, M. R. (1988) In The Evolution of Sex (eds. Michod, R. E., and Levin, B. R.). Sinauer Associates Inc., Massachusetts, pp. 161-175.

6) Kawano, S., Takano, H., Mori, K., and Kuroiwa, T. (1991) Physarum Newslet. 22, 70-75.

7) Kirouac-Brunet, J., Mansson, S., and Pallotta, D. (1981) Can. J. Genet. Cytol. 23, 9-16.

8) Kawano, S., Kuroiwa, T., and Anderson, R. W. (1987) J. Gen. Microbiol. 133, 2539-2546.

9) Nishibayashi, S., Kawano, S., and Kuroiwa, T. (1987) Cytologia 52, 599-614.

10) Youngman, P. J., Pallotta, D. J., Hosler, B., Struhl, G., and Holt, C. E. (1979) Genetics 91, 683-693.

11) Kawano, S., Takano, H., Mori, K., and Kuroiwa, T. (1993) Genetics 133, 213-224.

12) Takano, H., Kawano, S., Suyama, Y., and Kuroiwa, T. (1990) Curr. Genet. 18, 125-131.

13) Kawano, S., and Kuroiwa, T. (1989) J. Gen. Microbiol. 135, 1559-1566.

14) Takano, H., Kawano, S., and Kuroiwa, T. (1994) Curr. Genet. 26, 506-511.

15) Dee, J. (1982) In Cell Biology of Physarum and Didymium (eds. Aldrich, H. C., and Daniel, J. W.). Academic Press, New York, vol. 1, pp. 211-251.

16) Dee, J. (1987) Trends Genet. 3, 208-213.

17) Shinnick, T. M., Pallotta, D. J., Jones-Brown, Y. V. R., Youngman, P. J., and Holt, C. E. (1978) Curr. Microbiol. 1, 163-166.

18) Kawano, S., Anderson, R. W., Nanba, T., and Kuroiwa, T. (1987) J. Gen. Microbiol. 133, 3175-3182.

19) Takano, H., Mori, K., Kawano, S., and Kuroiwa, T. (1996) Curr. Genet. 29, 257-264.

20) Collins, O. R. (1975) Mycologia 67, 98-107.

21) Howard, F. L. (1931) Am. J. Bot. 18, 116-132.

22) Takano, H., Kuroiwa, T., and Kawano, S. (1997) Cell Struct. Func. 22, 299-308. 